\title{
O NEOCONSTITUCIONALISMO E SEUS IMPACTOS FRENTE AO TRABALHO INFANTOJUVENIL BRASILEIRO
}

\author{
NEOCONSTITUTIONALISM AND ITS IMPACTS IN CHILD AND ADOLESCENT'S \\ LABOUR IN BRAZIL
}

Karyna Batista Sposato Doutorado em Direito pela Universidade Federal da Bahia (2011), Mestrado em Direito pela Universidade de São Paulo (2003), Graduação em Direito pela Universidade de São Paulo (1997), professora permanente do Programa de Pós-Graduação em Direito (PRODIR) da Universidade Federal de Sergipe e Coordenadora dos Observatórios Sociais da mesma Universidade.

Marcelo Oliveira do Nascimento Mestrado em Direito pela Universidade Federal de Sergipe - UFS (2019), Especialização em Direito do Trabalho e Previdenciário pela Faculdade de Sergipe (2018), Graduação em Direito pela Faculdade de Sergipe (2015).

\begin{abstract}
Resumo
O presente artigo tem o objetivo de analisar o impacto do neoconstitucionalismo no enfrentamento do trabalho infantojuvenil no Brasil, partindo da hipótese de que esse fenômeno contribuiu com o sistema de proteção contra o trabalho precoce. Assim, pretende-se responder como tem se pautado o trabalho infantojuvenil e seu enfrentamento à luz da perspectiva do neoconstitucionalismo brasileiro. Fruto do desenvolvimento do constitucionalismo, a constitucionalização do Direito também será discutida no que tange aos direitos da criança e do adolescente, em especial sua influência nas normas de proteção ao trabalho da pessoa menor de dezoito anos de idade. Para tanto, foi utilizada a pesquisa bibliográfica como fonte principal, sustentada pela revisão do conteúdo na doutrina e na legislação. A partir de uma abordagem pelo método dedutivo, chegase à conclusão de que a constitucionalização do direito, fruto do neoconstitucionalismo, corroborou com a criação de mecanismos de combate ao problema, tais como normas jurídicas e políticas públicas.
\end{abstract}

Palavras chave: Constitucionalização do Direito. Neoconstitucionalismo. Trabalho Infantojuvenil

\begin{abstract}
This article aims to analyze the impact of neoconstitutionalism on coping with child labor in Brazil, based on the hypothesis that this phenomenon contributed to the protection system against early work.
\end{abstract}


Thus, we intend to answer how child and youth work has been guided and its confrontation in the light of the perspective of Brazilian neoconstitutionalism. As a result of the development of constitutionalism, the constitutionalization of law will also be discussed with regard to the rights of children and adolescents, especially its influence on the norms of labor protection of persons under eighteen years of age. To this end, bibliographic research was used as the main source, supported by the revision of the content in doctrine and legislation. From a deductive method approach, it is concluded that the constitutionalization of law, the result of neoconstitutionalism, corroborated the creation of mechanisms to combat the problem, such as legal norms and public policies.

Keywords: Child Labour. Constitutionalisation of Law. Neoconstitutionalism

\section{CONSIDERAÇÕES INICIAIS}

A Convenção Internacional dos Direitos da Criança, ratificada pelo Brasil em 1989, estabelece uma proteção para crianças e adolescentes contra a exploração do seu trabalho. Vários países ratificaram a Convenção e se propuseram a combater fortemente o trabalho infantojuvenil. O Brasil possui um arcabouço de normas protetivas que asseguram à criança e ao adolescente o direito ao desenvolvimento digno, sadio e com a inserção do trabalho de forma gradual para os adolescentes. Contudo, ao analisar os dados sobre o trabalho infantojuvenil, facilmente se constata que a realidade fática se apresenta dissonante das previsões normativas.

Internacionalizado, o combate ao trabalho infantojuvenil é uma difícil missão para inúmeros países. No Brasil, é uma realidade que afeta cerca de 1,8 milhão de crianças e adolescentes entre 5 e 17 anos $^{1}$.

Em concomitância, ocorre no ordenamento jurídico brasileiro o fenômeno do neoconstitucionalismo como decorrência de um intenso processo de releitura de todo o direito sob a ótica do texto constitucional. Em tempos remotos, o cidadão brasileiro, quando em dúvida acerca de qual direcionamento político e social seguir, logo indagava: o que pensa o imperador? O que diz o clero? O que impõe as forças armadas? O que dispõe a legislação ordinária? Diferentemente, hoje, pergunta-se: o que determina a Constituição Federal de 1988? Essa mudança de direcionamento e de perspectiva de futuro deve-se muito à centralidade atribuída ao texto constitucional

\footnotetext{
${ }^{1}$ De acordo com a Pesquisa Nacional por Amostra de Domicílio (PNAD) de 2016, realizada pelo Instituto Brasileiro de Geografia e Estatística (IBGE).
} 
na democracia brasileira, adotando-se a Constituição no eixo central do ordenamento jurídico.

Da análise do trabalho infantojuvenil, inicialmente, vislumbra-se que a constitucionalização do Direito da Criança e do Adolescente e a adoção de regras constitucionais protetivas aos menores de dezoito anos de idade frente a exploração de seu trabalho teve impacto importante para o reconhecimento de uma condição peculiar de desenvolvimento de infantes e jovens. Neste caminho, o presente texto discute a influência do neoconstitucionalismo no combate ao trabalho infantojuvenil.

O objeto principal da pesquisa foi a análise do trabalho infantojuvenil brasileiro, bem como o fenômeno do neoconstitucionalismo, num prisma amplo e associativo entre os temas para compreensão dos impactos gerados no enfrentamento ao problema. A hipótese a ser verificada é a de que o neoconstitucionalismo, e suas características peculiares, possibilitou a produção de mecanismos capazes de contribuir com o sistema de proteção contra o trabalho precoce no Brasil. Para a confirmação da hipótese, escolheu-se o método dedutivo, chegando-se à conclusão a partir do raciocínio lógico e associativo. Além disso, também foi utilizada a pesquisa bibliográfica como fonte principal de investigação, analisando-se o tema a partir da doutrina e da legislação vigente no Brasil.

$\mathrm{Na}$ primeira parte do trabalho é possível compreender como se operou a construção da infância na passagem da idade medieval para a modernidade, utilizando-se dos escritos de Phillippe Ariès. Ainda, esta primeira parte discorre sobre o conceito jurídico de criança e adolescente e quais os motivos para a definição etária desse conceito, com fulcro nas ideias de Jean Piaget e suas teorias acerca das fases do desenvolvimento humano.

No segundo momento, discute-se a problemática do trabalho infantojuvenil, como ela se conjectura, quais são suas causas, efeitos e as normas de proteção aplicáveis ao trabalho de menores de dezoito anos de idade. Por fim, aborda-se o neoconstitucionalismo e seus marcos (teóricos, históricos e filosóficos), suas principais características, efeitos, e quem são seus atores. Em síntese, trata-se de examinar os efeitos da Constitucionalização do Direito frente ao combate ao trabalho infantojuvenil para apontar suas contribuições e perspectivas.

\section{BREVES CONCEPÇÕES ACERCA DA INFÂNCIA E DA ADOLESCÊNCIA}




\subsection{A infância construída no marco da passagem para a modernidade}

Sabe-se através de importantes estudos históricos, principalmente do autor Philippe Ariès (2017), que nem sempre a infância e a adolescência foram vistas tal qual enxerga-se atualmente. Ariès destaca a modernidade como um marco para a mudança de perspectiva sobre o olhar acerca da infância, adolescência e juventude.

Em se tratando de modernidade, Touraine (1994) a define como uma época marcada pela racionalização e pela destruição de certas crenças e de culturas tradicionais incompatíveis com a razão, o que vem a contribuir para essa mudança de pensamento e compreensão.

Conforme Ariès (2017), a adolescência sequer, definidamente, existia antes da modernidade. Já a infância era reduzida ao período mais frágil do indivíduo, ou seja, quando ele ainda era um bebê. Assim, logo que a criança adquiria o mínimo de autonomia física, já era socializada juntamente com os adultos, partilhando de várias das suas atividades e experiências.

Neste compasso, a criança - praticamente bebê - logo se transformava em um indivíduo jovem, sem sequer viver a etapa da infância e adolescência, tal qual temos hoje na sociedade moderna. Não havia garantias para o desenvolvimento das crianças e adolescentes, tampouco para a sua sociabilização porque antes da modernidade não existia a concepção peculiar de desenvolvimento desses indivíduos. A infância, na velha sociedade tradicional, tornava-se praticamente insignificante e sem muita preocupação (ARIÈS, 2017).

Neste quadro, tem-se como consequência a hiperfragilização da infância na velha sociedade tradicional. Se hoje, mesmo com todos os cuidados que a sociedade passou a ter com a criança e o adolescente, ainda é possível apontar uma infância frágil, quem dirá num dado momento da história em que não havia tanta preocupação com esta fase do indivíduo.

Ariès (2017) destaca ainda que, como o sentimento entre cônjuges, pais, irmãos e demais familiares era desnecessário para com a criança, as interações afetivas do infante na velha sociedade tradicional se davam através do contato com os vizinhos, amos e criados, amigos e parentes diluídos nesse meio, em encontros tradicionais ou em festas e visitas ocasionais.

Phillippe Ariès chegou a estas conclusões analisando documentos e pinturas da época medieval na Europa, e, a partir disso, tentou, em seus estudos, interpretar a 
sociedade tradicional (medieval) para logo em seguida mostrar o novo lugar que a criança e o adolescente assumiram na sociedade moderna subsequente. Assim, Ariès (2017) aponta que a sociedade européia tradicional não compactuava com o mesmo conceito de infância pensado na modernidade.

Para o autor, as crianças da sociedade medieval não recebiam o mesmo tratamento e cuidado que recebem hoje, sendo geralmente vestidas como "mini adultos" e pintadas em diversas obras artísticas como trabalhadores do campo e comércio, do mesmo modo como os adultos, além de por vezes bebendo em festas e encontros. É importante destacar que esta visão ora apresentada ao longo da história, assim como a ausência do sentimento de infância e inocência das crianças antes da modernidade aqui destacada, sempre representa o registro através do olhar dos adultos, haja vista que a criança nunca foi capaz, até então, de registrar a sua própria história com sua própria voz e conforme a sua própria leitura de si mesma e das suas interações (ROCHA, 2002).

Partindo da mesma compreensão de Ariès, Shaffer (2005), aponta que a mudança desse pensamento apontado nos parágrafos anteriores passa a acontecer em decorrência da visão religiosa. A partir da ascensão e disseminação do Cristianismo, crianças passam a ser vistas como seres de almas frágeis, indivíduos inocentes que deveriam estar protegidos do mundo selvagem dos adultos. Assim, desenvolve-se a ideia de introduzir uma aprendizagem escolar para a criança, que receberia ensinamentos religiosos e morais, além de noções básicas de como escrever e ler, para culminar na transformação de crianças em adultos trabalhadores, dotados de servidão e de força trabalho essenciais para a sociedade.

Conforme a sociedade moderna se consolida, não somente esse sentimento de infância toma forma, mas também as definições etárias do conceito de criança, adolescente, jovem, adulto e idoso passam a ser consideradas, permitindo um tratamento diferenciado, pelas diversas ciências, para cada fase da vida do ser humano. É também a partir de critérios etários que direitos e garantias são estabelecidos, bem como responsabilidades imputadas.

\subsection{Conceito jurídico de criança e adolescente}

Com tantas menções aos termos criança e adolescente, importante se torna elucidar seu conceito jurídico. No âmbito global, a Convenção Internacional sobre os 
Direitos da Criança, ratificada pelo Brasil em 24 de setembro de 1990, trouxe logo em seu artigo primeiro a definição jurídica de criança como todo o indivíduo que possua menos de dezoito anos de idade, salvo quando a maioridade seja atingida antes da citada idade, com respaldo na legislação de cada país ${ }^{2}$. Assim, o texto da Convenção Internacional sobre os Direitos da Criança não diferenciou criança de adolescente, considerando, dessa forma, todos os menores de dezoito anos como crianças, independentemente da faixa etária que ocupem.

Já o Brasil foi além e optou por estabelecer uma divisão, também puramente etária, entre a criança e adolescente, definindo assim, conforme o artigo $2^{\circ}$ do $\mathrm{ECA}^{3}$, a criança como toda pessoa até doze anos de idade incompletos e adolescente aquela entre doze e dezoito anos de idade.

Portanto, é possível extrair que, de acordo com a legislação brasileira, conceitualmente, criança e adolescente representam significados distintos em decorrência de cada fase de desenvolvimento mental e físico que possuem.

Diversos são os estudos que compreendem o homem como um ser que possui várias fases diferentes de desenvolvimento ao longo da vida, sendo os mais comuns a infância, adolescência, juventude, adultez e maturidade. A respeito, é possível citar os estudos de Piaget (1999) para exemplificar os mais variados estágios do desenvolvimento humano:

\begin{abstract}
Distinguiremos, para maior clareza, seis estágios ou períodos do desenvolvimento, que marcam o aparecimento dessas estruturas sucessivamente construídas: $1^{\circ}$ o estágio dos reflexos, ou mecanismos hereditários, assim como também das primeiras tendências instintivas (nutrições) e das primeiras emoções. $2^{\circ} 0$ estágio dos primeiros hábitos motores e das primeiras percepções organizadas, como também dos primeiros sentimentos diferenciados. $3^{\circ}$ o estágio da inteligência sensomotora ou prática (anterior à linguagem), das regulações afetivas elementares e das primeiras fixações exteriores da afetividade. (...) $4^{\circ} \mathrm{o}$ estágio da inteligência intuitiva, dos sentimentos interindividuais espontâneos e das relações sociais de submissão ao adulto (de dois a sete anos, ou da segunda parte da 'primeira infância'). $5^{\circ}$ o estágio das operações intelectuais concretas (começo da lógica) e dos sentimentos morais e sociais de cooperação (de sete a onze-doze anos). $6^{\circ}$ o estágio das operações intelectuais abstratas, da formação da personalidade e da inserção afetiva e intelectual na sociedade dos adultos (adolescência) (PIAGET, 1999, P. 15).
\end{abstract}

\footnotetext{
${ }^{2}$ Convenção internacional sobre direitos da Criança, artigo primeiro: para efeitos da presente Convenção considera-se como criança todo ser humano com menos de dezoito anos de idade, a não ser que, em conformidade com a lei aplicável à criança, a maioridade seja alcançada antes.

${ }^{3}$ Estatuto da Criança e do Adolescente, artigo segundo: considera-se criança, para os efeitos desta Lei, a pessoa até doze anos de idade incompletos, e adolescente aquela entre doze e dezoito anos de idade.
} 
Piaget (1999) destaca seis estágios bem definidos do indivíduo, desde o seu nascimento, até os doze anos de idade. Tais estágios do desenvolvimento humano são gradativos (na maioria deles uma característica concebida em um, continua, gradativamente, desenvolvendo-se no outro) e possuem grande relevância na Educação e na Psicologia, por exemplo. Entretanto, no que diz respeito ao aspecto jurídico, interessaria diferenciar ${ }^{4}$, para a legislação, aqueles que possuem uma característica muito distinta. Quanto a isso, os estudos de Piaget (1999) apontam um salto de mudança brusca no comportamento e na mentalidade dos indivíduos a partir de doze anos de idade. É justamente a partir dessa idade que o indivíduo começa a desenvolver pensamentos mais complexos, podendo enxergar a sociedade a partir de si mesmo e da sua própria forma de apreensão de conhecimento, porém, ainda sem a formação completa de um adulto.

Definir objetivamente uma criança ou adolescente através de um critério puramente etário pode ensejar, em algum momento ou numa determinada área, equívocos e erros quanto ao tratamento individual de cada ser humano, isto porque a infância pode representar algo muito subjetivo e particular de cada pessoa. Acerca dessa tenuidade no conceito de infância, assim ensina Reis:

\begin{abstract}
A infância pode ser definida em função da idade, mas diversas sociedades aplicam critérios distintos para estabelecer o limite entre a infância e a idade adulta. Em certas sociedades, no entanto, idade não constitui base suficiente para determinar a infância. O cumprimento de determinados ritos sociais e obrigações tradicionais podem também ser requisito para a definição do estado de adulto ou de criança. Em outras, a integração da criança na vida socioeconômica pode começar tão cedo ou a transição da infância pra idade adulta pode ser tão lenta e gradual que é praticamente impossível identificar claramente as etapas da vida (REIS, 2011, p. 26).
\end{abstract}

Contudo, subjetivar demais as fases de cada indivíduo em desenvolvimento poderia trazer um problema grave de ineficácia para o Direito, ao qual ainda não se teria uma solução. Na tentativa de equacionar o problema e aproximar-se do equilíbrio, o ordenamento jurídico brasileiro, conforme o já mencionado artigo segundo do ECA, preferiu tratar os menores de dezoito anos em parte como criança (até os

\footnotetext{
${ }^{4}$ Com o passar dos anos, a legislação brasileira avançou e passou a adotar leis específicas para resguardar as diversas fases do desenvolvimento humano. Como exemplo tem-se a lei da primeira infância (13.257/2016), que estabelece, conforme artigo primeiro "princípios e diretrizes para a formulação e a implementação de políticas públicas para a primeira infância em atenção à especificidade e à relevância dos primeiros anos de vida no desenvolvimento infantil e no desenvolvimento do ser humano". Também recentemente, em 2013, o Estado Brasileiro aprovou a lei 12.852, que institui o Estatuto da Juventude, considerando abrangidas por esta lei as pessoas consideradas jovens as que tiverem idade entre 15 (quinze) e 29 (vinte e nove) anos.
} 
doze anos incompletos), noutra como adolescentes (dos doze até os dezoito anos), sem prejuízo da diferenciação de direitos e responsabilidades a partir de diversas idades (responsabilidade por atos infracionais, aos 12 anos ${ }^{5}$; capacidade para o trabalho, a partir dos 14, na forma de aprendiz; capacidade eleitoral ativa, a partir dos 16 anos $^{6}$; etc).

Assim, pelo importante motivo de que o tratamento dado ao indivíduo nas suas diferentes fases de desenvolvimento infantojuvenil refletirá de maneira drástica na sua condição de futuro adulto é que o ECA diferencia a criança e o adolescente, sendo mais adequado resguardar os direitos de cada indivíduo conforme a etapa de desenvolvimento em que ele se encontra.

É possível também vislumbrar essa opção da legislação brasileira através do viés penalista, em que se adota uma posição garantista em sua concepção, conforme ensinamentos de João Batista Costa Saraiva:

A opção legislativa brasileira de fixar a adolescência no período compreendido entre a zero hora do dia em que a criança completa 12 anos até o instante antecedente à zero hora do dia em que o adolescente completa dezoito anos, se constitui em decisão de política criminal. Opção adequada e consentânea à ordem jurídica internacional, nos termos da própria Convenção das Nações Unidas de Direitos da Criança; e garantista em sua concepção posto que supera o reducionista critério biopsicológico sobre o discernimento, aquele adotado no Brasil ao tempo do Código Penal do Império e abandonado por inadequado e arbitrário ainda na primeira metade do século XX (SARAIVA, 2010, p. 32).

Assim, o tratamento dado à pessoa nas suas diferentes fases de desenvolvimento infantojuvenil, sob as várias perspectivas do Direito, reflete drasticamente na sua condição de futuro adulto. Por isso, a criança e o adolescente precisam ter suas necessidades atendidas em suas mais variadas formas.

As proteções e garantias fundamentais resguardadas pela legislação incluem, para que cada momento da vida do indivíduo seja respeitado, a inserção de atividades (educação, lazer, trabalho, esporte, etc.) moderadamente adequadas à determinada faixa etária. A esse respeito, dentre diversos temas, surge então uma problemática do trabalho infantojuvenil: quando e de que forma o indivíduo deve começar a trabalhar?

\footnotetext{
${ }^{5}$ Constituição Federal, artigo 228: são penalmente inimputáveis os menores de dezoito anos, sujeitos às normas da legislação especial. Estatuto da Criança e do Adolescente, artigo 105: ao ato infracional praticado por criança corresponderão as medidas previstas no art. 101.

${ }^{6}$ Constituição Federal de 1988, artigo 14 , parágrafo $1^{\circ}$, inciso I: a soberania popular será exercida pelo sufrágio universal e pelo voto direto e secreto, com valor igual para todos, e, nos termos da lei, mediante: $\S 1^{\circ} \mathrm{O}$ alistamento eleitoral e o voto são: I - obrigatórios para os maiores de dezoito anos.
} 


\title{
3. O PROBLEMA DO TRABALHO INFANTOJUVENIL NO BRASIL
}

\subsection{Conceito normativo de trabalho infanto-juvenil}

O trabalho em condições impróprias para sua condição etária pode causar diversos problemas e comprometer o futuro das crianças e adolescentes, isto porque o trabalho é fator importante na construção psíquica e social do ser humano. Assim, o ingresso no mercado de trabalho deve ser feito com respeito às condições físicas e intelectuais, respeitando a proteção dos seus direitos e garantias fundamentais constitucionalmente instituídos, de modo que não lhes cause prejuízo futuro.

A iniciação ao trabalho é, inegavelmente, um momento imprescindível na vida dos menores de dezoito anos, porém esse ingresso deve acontecer, saudavelmente, na fase correta correspondente a sua vida. De acordo com Ozella (2003), o homem produz seus bens, ideias e a si próprio a partir do trabalho e das relações sociais que os jovens estabelecem em seu cotidiano. $O$ referido autor continua refletindo sobre a importância do trabalho como fonte de construção social e psíquica:

\begin{abstract}
A partir do trabalho, o homem não somente se constrói como, também, cria relações com outros homens. Nesse Processo único, os homens se reconhecem como tal, enquanto trabalhadores, cidadãos. Portanto, 0 trabalho como atividade humana, como constituição de si mesmo ou como produção material, propicia o caminhar lado a lado das construções concretas e intelectuais. Deste modo, todo e qualquer trabalho contribui para a estruturação do psiquismo e existência humana (Ozella, 2003, P. 278.)
\end{abstract}

A problemática da exploração do trabalho de crianças e adolescentes situa-se nesta seara de intersecção entre as relações sociais, culturais e trabalhistas protegidas pelos direitos humanos. Explorar o trabalho de menores de dezoito anos e submetê-los à condição incompatível com seus direitos e garantias fundamentais é também ferir visceralmente o princípio da dignidade da pessoa humana. Buscando medir e comparar a valoração desse princípio, assim reflete Piovesan:

[...] infere-se que o valor da dignidade da pessoa humana e o valor dos direitos e garantias fundamentais vêm a constituir os princípios constitucionais que incorporam as exigências de justiça e dos valores éticos, conferindo suporte axiológico a todo o sistema jurídico brasileiro (PIOVESAN, 2013, p. 90).

A dignidade da pessoa humana constitui-se em importante princípio norteador 
das atividades laborais dos infantes e adolescentes. Mas, não somente isso, o valor desse referido princípio é luz que clareia toda a ordem jurídica, sendo ponto de partida e de chegada na tarefa da interpretação normativa contemporânea (TREVISAM, 2015).

No tocante ao labor do menor de dezoito anos, Leite (2017) correlaciona o princípio da dignidade da pessoa humana ao princípio do valor social do trabalho para asseverar que o labor não é meramente uma mercadoria porque possui um valor social. Procede o autor argumentando que para representar um valor social, o labor necessariamente precisa dignificar o ser humano, de modo que todo trabalho que não é decente (trabalho infantil, análogo ao de escravo, degradante, em jornadas insuportavelmente exaustivas, dentre outros) não dignifica o ser humano e, portanto, viola tanto o princípio da dignidade da pessoa humana, quanto o do valor social do trabalho.

Por isso, em conformidade com a dignidade da pessoa humana, a atividade laborativa, no Brasil, é terminantemente proibida para crianças e regulamentada para os adolescentes a partir de quatorze anos de idade, sendo esta proteção considerada um direito fundamental na medida em que é capaz de propiciar meios para uma existência digna, conforme artigo $7^{\circ}$, inciso XXXIII, da Constituição Federal ${ }^{7}$ e do artigo 60 do Estatuto da Criança e do Adolescente ${ }^{8}$.

No tocante à regulamentação do trabalho, é vedado, pela legislação brasileira, o trabalho noturno, perigoso ou insalubre aos menores de dezoito anos e de qualquer trabalho aos menores de dezesseis anos, salvo na condição de aprendiz, a partir de quatorze anos, também conforme os já mencionados artigos $7^{\circ}$, inciso XXXIII, da Constituição Federal, e artigo 60 do ECA.

Além disso, por força da legislação, também são proibidos o trabalho penoso para os menores de dezoito anos e o trabalho em subsolos para os menores de vinte e um anos de idade ${ }^{9}$. Cassar (2017) colaciona outras atividades laborais que o jovem

\footnotetext{
${ }^{7}$ Artigo $7^{0}$ da Constituição Federal: São direitos dos trabalhadores urbanos e rurais, além de outros que visem à melhoria de sua condição social: XXXIII - proibição de trabalho noturno, perigoso ou insalubre a menores de dezoito e de qualquer trabalho a menores de dezesseis anos, salvo na condição de aprendiz, a partir de quatorze anos. Artigo 403 da CLT: é proibido qualquer trabalho a menores de dezesseis anos de idade, salvo na condição de aprendiz, a partir dos quatorze anos.

${ }^{8}$ Art. 60 . É proibido qualquer trabalho a menores de quatorze anos de idade, salvo na condição de aprendiz.

${ }^{9}$ Artigo 301 da CLT: O trabalho no subsolo somente será permitido a homens, com idade compreendida entre 21 (vinte e um) e 50 (cinquenta) anos, assegurada a transferência para a superfície nos termos previstos no artigo anterior.
} 
adulto menor de vinte e um anos não está apto a realizar, tais quais: peão de rodeio; vigilante, propagandista e vendedor de produtos farmacêuticos e motoboy ou mototaxista.

Segundo Barros (2016), essas restrições se justificam devido ao organismo do indivíduo não reagir como o de um adulto, haja vista que ainda está em crescimento, necessitando de uma defesa mais madura. Já Pessoa e Sousa (2016) complementam que tal proteção deriva do interesse público da preservação da mão-de-obra futura e higidez das crianças, adolescentes e jovens. Acerca da proibição do trabalho do menor de 16 anos, assim argumenta Maurício Godinho Delgado:

É evidente que os limites etários constitucionais aplicam-se a qualquer modalidade de labor do jovem brasileiro (qualquer trabalho, enfatiza o art. $7^{\circ}$, XXXIII, CF/88). Tratando-se de vínculo empregatício clássico, o novo limite constitucional, desde a EC n. 20/1998, é a idade de 16 anos (o texto original de 1988 previa 14 anos, como já dito). Tratando-se de contrato de aprendizagem, este limite, desde a mesma EC n. 20, é de 14 anos (o texto original da Constituição estipulava 12 anos) (DELGADO, 2017, p. 916).

Assim, Leite (2017) organiza o trabalho do menor de dezoito anos em: a) adolescente empregado, aquele que possui uma relação de emprego com idade entre dezesseis e dezoito anos, sendo-lhes assegurados os mesmos direitos trabalhistas e previdenciários de um trabalhador maior de dezoito anos; e b) adolescente aprendiz, aquele que entre quatorze e dezoito anos (com exceção do aprendiz deficiente, cuja idade se estende aos vinte e quatro anos de idade) possui um contrato de aprendizagem, conforme artigo 428 da CLT, combinado com o artigo 62 do ECA, sendo-lhes assegurados todos os direitos trabalhistas e previdenciários. Para além disso, o trabalho do menor de dezoito anos é totalmente proibido pela legislação trabalhista, salvo, em casos específicos e autorizados pelo juiz da vara da infância e juventude, de trabalhadores infantojuvenis artísticos ${ }^{10}$.

Às normas de ordem nacional se acrescem outras de ordem internacional que reforçam a proibição do trabalho infantojuvenil. Assim, destaca-se a convenção $n^{\circ} 138$ da OIT, aprovada no Brasil pelo Decreto Legislativo n. 179, de 14.12.1999, do

\footnotetext{
${ }^{10}$ Conforme análise de Cavalcante (2013), a legislação brasileira encontra respaldo para o trabalho de crianças em empreendimentos artísticos nas normas internacionais, como a Convenção 138 da OIT, ratificada pelo Brasil por meio do decreto 4.137/2002, que também promulgou a recomendação $n \circ 146$ da OIT - acerca da idade mínima para atividades laborais. Essa normativa dispõe sobre a idade mínima de admissão ao emprego e autoriza de forma expressa que uma criança possa exercer um trabalho com finalidades artísticas, mesmo que não possua a idade mínima prevista na convenção 138 da OIT, no artigo $8^{\circ}$. Esse dispositivo tem sido denominado pela doutrina como cláusula de exceção, pois estabelece uma flexibilização na norma proibitiva.
} 
Congresso Nacional, e em vigor desde 25 de junho de 2002, que dispõe sobre a idade mínima para admissão ao trabalho ${ }^{11}$, que, conforme $o$ item 3 do artigo $2^{\circ}$, não será inferior a idade em que o adolescente concluir a escolaridade obrigatória, ou, em qualquer outra hipótese, não menor do que quinze anos.

O Brasil possui uma legislação mais protetiva do que dispõe a Convenção 138 da OIT, pois em todo território nacional a idade mínima para o trabalho é de dezesseis anos de idade. A referida convenção dispõe ainda que o país membro que promulgue a normativa, instaure uma política para, em condições favoráveis, e, progressivamente, elevar a idade mínima de admissão ao trabalho.

Outra normativa internacional de destaque é a Convenção $n^{\circ} 182$ da OIT, que versa sobre a proibição das piores formas de trabalho infantil, aprovada pelo decreto legislativo n. 178, de 1999, e em vigor desde 2001. Segundo a Convenção, podem ser enquadradas como piores formas de trabalho infantil: a) trabalho análogo ao de escravo, o que inclui o tráfico de crianças, servidão, trabalhos forçados ou obrigatórios para utilização da mão de obra em conflitos armados; b) prostituição ou produção de pornografia infantil; c) envolvimento em atividades ilícitas, o que inclui o tráfico de entorpecentes; e d) trabalhos suscetíveis de prejuízos da saúde, moral e segurança da criança. Neste último tópico, a depender da atividade, pode-se incluir o trabalho em feiras livres.

A Convenção dispõe ainda que o Estado que ratificar a convenção precisa adotar medidas tanto imediatas quanto eficazes para proibir e eliminar as formas de trabalho elencadas no parágrafo acima. Visando cumprir este item, o Brasil, além de proibir taxativamente todas essas formas de trabalho, implementou o Programa de Erradicação do Trabalho Infantil (PETI), cujo objetivo é justamente eliminar as piores formas de trabalho e ampliar as políticas públicas sociais voltadas ao adequado desenvolvimento das crianças e adolescentes.

\subsection{Panorama da realidade brasileira acerca do trabalho infantojuvenil}

Diante de todo esse arcabouço normativo, importante se faz analisar os dados estatísticos oficiais acerca do trabalho infantojuvenil. No Brasil, os dados oficiais são

\footnotetext{
${ }^{11}$ No que se refere a idade mínima para admissão ao trabalho, alguns países têm adotado a sua própria regra. Sérgio Pinto Martins (2015, p. 145) elenca alguns países, tais como: Argentina (14), Alemanha (15), Bélgica (15), China (16), França (16), Japão (15), Portugal (16), Síria (14), Tunísia (16).
} 
do IBGE, na Pesquisa Nacional por Amostra de Domicílios Contínua - PNADC, de $2016^{12}$. Os números oficiais apontam para 1,8 milhão de crianças e adolescentes em situação de trabalho, com faixa etária entre 5 e 17 anos de idade, o que demonstra que o Brasil possui uma taxa de trabalho infantojuvenil de $4,6 \%$, haja vista que o país conta com uma população de jovens entre 5 e 17 anos de 40,1 milhões. Contudo, é importante ressaltar que para adequar o conceito de trabalho infantojuvenil aos padrões internacionais, o IBGE modificou a definição a partir do PNADC 2016, eliminando dos dados estatísticos o trabalho para consumo próprio realizado por crianças e adolescentes. Assim, o IBGE passou a contabilizar este tipo de trabalho não mais como trabalho infantil, mas sim como "outras formas de trabalho", que inclui a categoria produção para próprio consumo ${ }^{13}$.

A modificação citada no parágrafo anterior gerou uma diminuição - mascarada - substancial dos dados acerca do trabalho infantil de 2016, com relação ao ano anterior, quando o IBGE ainda utilizava a metodologia de contabilização estatística que incluía o trabalho para o próprio consumo de crianças e adolescentes também como trabalho infantil. Assim, se a produção para próprio consumo fosse considerada, o Brasil passaria a ter cerca de 2,5 milhões de crianças e adolescentes, de 5 a 17 anos, realizando atividades laborais.

Em termos de porcentagem, avaliando as faixas etárias da pesquisa do IBGE, das cerca de 2,3 milhões de crianças e adolescentes em situação de trabalho no Brasil, $57,07 \%$ tem idade entre 16 e 17 anos; $24,05 \%$ entre 14 e 15 anos; $14,51 \%$ entre 10 a 13 anos e 4,35\% entre 05 e 09 anos. Em se tratando de recorte por gênero, $64,2 \%$ eram do sexo masculino e $35,8 \%$ eram do sexo feminino. Já no que diz respeito ao trabalho infantojuvenil por região geográfica, o Nordeste concentra $33 \%$ das crianças e adolescentes trabalhadores, seguido pela região Sudeste com $28,8 \%$, e em seguida região Sul com 16,1\%, Norte com 14,9\% e Centro Oeste com $7,2 \%$.

\footnotetext{
12 Todos os dados acerca do trabalho infantojuvenil colacionados neste trabalho, com referência da Pesquisa Nacional por Amostra de Domicílios Contínua (PNADC), de 2016, foram extraídos do III Plano Nacional de Prevenção e Erradicação do Trabalho Infantil e Proteção ao Adolescente Trabalhador, elaborado em 2018, com vigência para os anos de 2019 e 2022.

${ }^{13}$ O termo "produção para o próprio consumo" representa, para o IBGE, toda e qualquer atividade desenvolvida com o intuito de que aquilo que foi produzido seja consumido pelo produtor e sua família, apenas. Ou seja, tudo aquilo que é produzido serve para o próprio sustento. Geralmente, essas atividades incluem o cultivo agrícola, a criação de animais, pesca, fabricação de artigos para vestuário e móveis para uso próprio. Desta maneira, criticamente, essa metodologia pode deixar de considerar o trabalho de parte expressiva das crianças e adolescentes brasileiras, muitas, inclusive, exploradas e incluídas nas piores formas de trabalho infantil, e, consequentemente, excluídas das ações e programas governamentais de prevenção e erradicação do trabalho infantil.
} 
Quanto ao critério de raça ou cor, $66,2 \%$ é autodeclarada preta ou parda, 33,3\% branca, e $0,3 \%$ indígena. Outro dado interessante diz respeito ao vínculo empregatício, pois segundo esse critério, 83,3\% dos adolescentes entre 14 e 17 anos não possuía um contrato formal de trabalho, com assinatura da CTPS, enquanto que apenas $16,7 \%$ possuíam um vínculo com assinatura da carteira de trabalho.

Por fim, uma análise do perfil econômico das famílias com crianças e adolescentes envolvidos no trabalho demonstra que $77,6 \%$ das famílias recebem até um salário mínimo, 20,1\% recebem mais de um e até três salários mínimos, enquanto que apenas $2,3 \%$ recebem mais do que três salários mínimos.

Assim, é possível concluir que o perfil do trabalhador infantojuvenil brasileiro é representado, em sua maioria, por indivíduos de 10 a 15 anos (excetuando-se o trabalho de adolescentes entre 16 e 17 anos, cujo trabalho já é permitido para algumas situações), do sexo masculino, que habitam na região Nordeste, autodeclarados pretos ou pardos, sem contrato de trabalho formal (sem assinatura da CTPS) e cujas famílias recebem até um salário mínimo.

Ao confrontar o teor dos dados acerca do trabalho infantojuvenil com a legislação brasileira, observa-se um enorme descompasso entre a realidade fática e as previsões normativas. É certo que o trabalho de crianças e adolescentes em condições degradantes viola direitos fundamentais e as despoja do desfrute de uma infância e adolescência saudáveis e propícias ao momento da vida e para o melhor desenvolvimento social, mental e físico. Em suas formas mais extremas, crianças e adolescentes são expostas a riscos e doenças que atentam contra a sua vida, fazendo com que deixem de exercer, inclusive, a sua liberdade ao se enquadrarem em situações análogas à escravidão.

Os riscos à integridade física e mental da criança e do adolescente que exerce atividades laborais são inúmeros. Dentre eles, pode-se destacar o desenvolvimento de doenças relacionadas ao trabalho (ocupacionais), a exemplo de perda auditiva e lesões por esforços repetitivos. Ainda, a depender de cada atividade desempenhada, há riscos de problemas na coluna vertebral, amputação de membros, perda de dedos, ou desenvolvimento de doenças psicossomáticas como ansiedade e depressão. Soma-se a isso o descumprimento de normas básicas de saúde e segurança no trabalho, visto que, em regra, tais atividades laborativas não estão sob a vigilância de órgãos fiscalizadores.

Além dos riscos inerentes à saúde, o trabalho precoce e as relações laborais 
forçadas, além de interromper etapas no desenvolvimento infantojuvenil para que o indivíduo se adeque ao padrão do mercado de trabalho, podem comprometer o desenvolvimento intelectual do indivíduo, afetando na forma como ele enxerga o mundo, anulando possibilidades futuras de ascensão social, principalmente quando a criança ou o adolescente abandona a escola para trabalhar.

Outra consequência nefasta do trabalho infantojuvenil é a perpetuação da pobreza, que possui uma relação tão estreita com o tema que se transforma em causa e consequência ao mesmo tempo. De qualquer maneira, infantes, jovens e até mesmo os pais e parentes, parecem ignorar os riscos, ou assumi-los em virtude da necessidade financeira, que é um dos principais motivos para o trabalho precoce.

Existem diversas razões para que as crianças e adolescentes ingressem no mercado de trabalho de forma precoce e irregular. A condição financeira, atrelada à expectativa do mercado de trabalho capitalista por mão-de-obra barata, podem ser consideradas como as principais. A condição de pobreza a que está submetido o menor de dezoito anos, que precisa trabalhar para ajudar a compor a renda familiar, evidencia que o trabalho precoce alimenta um grande ciclo vicioso que corrobora para a perpetuação da exclusão social e da pobreza, e que acarreta numa série de problemas físicos e psicológicos.

Sarlet (2011) assevera que a pobreza ocasiona exclusão social e consequentemente a violação da dignidade da pessoa humana, visto que a falta de garantia aos direitos sociais decorrentes de decisões políticas pode resultar na condenação de pessoas à pobreza e no desrespeito aos direitos humanos desses indivíduos.

Deste modo, a criança ou adolescente encontram barreiras difíceis de transpor para ascender socialmente. Dois motivos explicam esta realidade: o primeiro porque a condição de pobreza os empurra para o mercado de trabalho informal, tomando seu tempo na dedicação dos estudos ou outras atividades importantes para o desenvolvimento físico e cognitivo sadio; e segundo porque a própria pobreza, por si só, Ihes priva de desenvolver suas potencialidades em decorrência da dificuldade de acessar ferramentas de desenvolvimento pessoal. Assim, o indivíduo mergulha no que se pode chamar de ciclo de pobreza causado pelo labor infantojuvenil. Desta maneira, enquanto a criança e o jovem pobre lutam para conseguir sobreviver, anulando o desenvolvimento de potencialidades, o economicamente mais favorecido desfruta de um ambiente favorável e que o possibilitará manter-se no topo da cadeia produtiva. 
O trabalho infantojuvenil não possui apenas fatores econômicos atrelados a sua causa, isto porque também é possível constatar o labor de crianças e adolescentes em famílias economicamente mais estruturadas. É o caso do trabalho doméstico, realizado em sua maioria por infantes e adolescentes do sexo feminino e ligado a um fator cultural da sociedade patriarcal atual, que vê nas meninas a responsabilidade de cuidar dos afazeres domésticos e dos mais jovens membros da família.

Submeter crianças a qualquer tipo de trabalho, ou adolescentes a trabalhos irregulares, pode causar danos irreversíveis à saúde física e mental desses indivíduos, comprometendo seu pleno desenvolvimento ao afetar a capacidade de aprendizagem ou socialização. $O$ trabalho infantojuvenil irregular representa a negação de direitos às crianças e aos adolescentes, além de condená-las a um tipo de vida que elas não puderam escolher.

Através do trinômio (Estado, família e sociedade) de responsabilidade da proteção de crianças e adolescentes previsto no artigo 227 da Constituição Federal, o encargo da crueldade e da exploração desses jovens não se restringe ao Estado, mas também às famílias e a toda a sociedade, que devem estar imbuídas no sentimento de erradicação dessas formas de trabalho. Entidades nacionais e internacionais esforçam-se para minimizá-lo e erradicá-lo, mas o esforço deve ser coletivo, principalmente quando estas formas laborais impedirem a efetivação de inúmeros direitos fundamentais.

Ainda, crianças e adolescentes são cotidianamente explorados e postas para realizar trabalhos incompatíveis com suas condições físicas e psicológicas, sem que o fato cause repulsa por parte de muitas pessoas. Isto se explica pela naturalização social do trabalho em que parte da população está mergulhada, acreditando que é melhor ver a criança trabalhando do que realizando atividades ilícitas, como se essas fossem as únicas opções possíveis. Sente sentido, Moreira e Custódio (2018) destacam alguns mitos que servem de guias para que as pessoas justifiquem a prática do trabalho infantojuvenil:

Dentre os principais mitos, cita-se: "O primeiro mito: é melhor trabalhar do que roubar"; "O segundo mito: o trabalho da criança ajuda a família"; "O terceiro mito: é melhor trabalhar do que ficar nas ruas"; "O quarto mito: lugar de criança é na escola"; "O quinto mito: trabalhar desde cedo acumula experiência para o futuro"; "O sexto mito: é melhor trabalhar do que usar droga"; "O sexto mito: trabalhar não faz mal a ninguém" (CUSTÓDIO; VERONESE, 2013, p. 93-108). Tais afirmativas são consideradas mitos por 
não condizerem com a verdade, criando-se a ilusão de que o trabalho infantil contribuiria para a solução dos problemas atinentes a pobreza e o desenvolvimento da pessoa humana, tentando justificar o injustificável, devido a uma cultura permissiva ao trabalho infantil que se prolifera na sociedade, fruto do modelo capitalista dominante, que em muito contribui para as desigualdades e exclusões, mas que não soluciona nenhum dos problemas acima citados, mas que traz muitas consequências negativas para crianças e adolescentes (MOREIRA e CUSTÓDIO, 2018, p. 190-191).

O problema do trabalho infantojuvenil irregular se arrasta há séculos, tendo convivido contemporaneamente com vários sistemas econômicos, jurídicos e sociais. Entretanto, o neoconstitucionalismo, ao menos em tese, aparenta ser um forte aliado na erradicação do trabalho infantojuvenil irregular e violador de direitos fundamentais.

\section{NEOCONSTITUCIONALISMO E O ENFRENTAMENTO AO TRABALHO INFANTOJUVENIL}

\subsection{Aspectos históricos e teóricos do Neoconstitucionalismo}

O neoconstitucionalismo caracteriza-se pelo conjunto de transformações do Estado de Direito, principalmente no que diz respeito à Constituição, operando uma transição do Estado Legislativo de Direito, com destaque para os legisladores e também com foco na lei como vontade popular, para dar espaço ao Estado Constitucional de Direito, tendo como centro do ordenamento jurídico a Constituição, dotada de força suprema (GONTIJO, 2015).

Essa nova forma do Direito Constitucional possui como grande marco histórico, na Europa, o constitucionalismo praticado após a Segunda Guerra mundial, com destaque para Alemanha e Itália, países arrasados por regimes autoritários. Foi preciso que a Constituição assumisse papel central no Direito europeu para restabelecer a democracia e reorganizar a política, implementando assim o Estado Constitucional (BARROSO, 2005).

[...] para que se viabilizasse uma leitura moral do Direito, com a inclusão dos valores na sua interpretação e na sua aplicação, foi necessário elaborar um redesenho dos ordenamentos jurídicos vigentes à época, objetivando alocar a Constituição no ponto central e mais importante do ordenamento, estabelecer como essência e fim desse sistema político-jurídico o homem, por meio do resguardo da sua dignidade e de seus direitos fundamentais, o que mostra sua vocação axiológica, e a inclusão, nos documentos normativos, de princípios e de conceitos jurídicos indeterminados, de forma a possibilitar um 'espaço' maior de interpretação e raciocínio jurídico do intérprete e aplicador do Direito, criando-se uma nova dogmática de 
hermenêutica constitucional (GONTIJO, 2015, p. 33).

Barroso (2015) aponta como referência desse ainda recente Direito Constitucional, surgido na Europa, a Lei Fundamental de Bonn ${ }^{14}$, em 1949, e, por conseguinte, a instalação do Tribunal Constitucional Federal (1951), que possibilitou a crescimento da produção científica do Direito Constitucional baseado em teorias e jurisprudências. Barroso (2015) destaca ainda, nesse novo constitucionalismo, a Constituição da Itália (1947) e a criação da sua Corte Constitucional (1956); a Constituição portuguesa de 1976; e a espanhola, em 1978. Do mesmo modo, Gontijo (2015) valoriza as citadas Constituições, mas destaca também, na América do Sul, a Constituição Brasileira de 1988. Acerca da força dessas novas constituições, assim destaca Gontijo:

As constituições europeias, neste contexto, do ponto de vista material, deixam de ser meros documentos retóricos e de inspiração política e passam a ter força normativa, aplicação de seus preceitos (especialmente dos direitos fundamentais) aos casos concretos, servindo necessariamente de referência e de orientação à produção, à interpretação e à aplicação das normas infraconstitucionais, em razão de sua característica de centralidade do sistema (GONTIJO, 2015, p. 34).

Após o advento da Constituição Brasileira de 1988, o direito constitucional no Brasil também ganha destaque, fazendo brotar no povo brasileiro um sentimento constitucional diferente do que se via em gerações passadas. Barroso (2015) vê esse sentimento como algo bastante introvertido, mas verdadeiro, que culmina no respeito, em tese, da Constituição, além de ser capaz de produzir esperança de que a Carta Magna realmente consiga resolver parte dos problemas estruturais brasileiros. Já Neto (2016) utiliza a expressão constitucionalismo brasileiro tardio para designar os porquês do Brasil possuir, ainda, um sentimento constitucional modesto. Para defender sua tese, Neto (2016) elenca causas históricas, jurídicas e políticas como principais responsáveis pela ausência de um efetivo sentimento constitucional no Brasil.

Neto (2016) aponta como principal causa histórica do constitucionalismo brasileiro tardio a ausência de pertencimento do povo brasileiro (especialmente negros e indígenas) ao longo da história, consolidando uma repulsa dos habitantes pelo modo como se desenvolveu a exploração da colônia pelos portugueses, sem a

\footnotetext{
${ }^{14}$ A Lei Fundamental de Bonn corresponde a Constituição, promulgada em 22 de maio de 1949, na Alemanha Ocidental.
} 
apresentação de um projeto, o que gerou, segundo o autor, a falta de consciência constitucional. Como principal causa política, Neto (2016) indica o frágil desenvolvimento da república e da ideia de democracia brasileira, que culminou num diminuto nível de sentimento constitucional. Ou seja, o autor aponta que o Brasil não possui uma consciência democrática consolidada, o que torna a população cética quanto ao trabalho das instituições e dos agentes políticos. Por fim, como consequência jurídica, Neto (2016) deduz que o individualismo jurídico brasileiro foi de fundamental importância para o constitucionalismo brasileiro tardio, pois os valores constitucionais e de interesse da coletividade estão dissociados de uma ideia individualista do direito.

O grande problema enfrentado por Neto (2016) é o de que a ausência desse sentimento constitucional frente a uma Constituição dirigente e analítica pode significar a derrocada da eficácia do texto constitucional, o que faz a Constituição se transformar em mera proposição utópica, sem efetividade na sua aplicabilidade.

Em que pesem as críticas, o neoconstitucionalismo se instala como fenômeno atrelado ao pós positivismo. No aspecto teórico, Moreira (2008) aponta alguns marcos, tais quais: a) presença da constituição em todos os ramos do Direito, seja em causas de grande relevância social, ou naquelas de cunho individual; b) intensificação da presença judicial, concomitantemente à diminuição da autonomia irrestrita do legislador; c) revisão da teoria da interpretação, com foco na ampliação do papel da hermenêutica constitucional; d) destaque para os direitos e princípios fundamentais, em prejuízo da aplicação das regras aplicadas no "tudo ou nada", para aumentar o enfrentamento dos casos concretos através da ponderação; e) Percepção de interpretação do Direito e da resolução dos problemas fora do ambiente exclusivamente judicial.

Já Barroso (2005) apresenta três grandes marcos teóricos do neoconstitucionalismo, quais sejam: a) o peso da força normativa da Constituição; b) a extensão da jurisdição constitucional; e c) o desenvolvimento de uma nova ordem de interpretação constitucional. Incontestavelmente, as constituições são as grandes protagonistas desse novo processo constitucional chamado de Neoconstitucionalismo.

Ferreira (2016) vai além e explica que a Constituição caracteriza-se por ser uma escolha política pautada na organização dos poderes e garantia de direitos, sendo ela sistemática, racional e associada a diversos processos, dentre eles o 
transconstitucionalismo, para além de uma ideia puramente neoconstitucional, conforme explica o autor:

A Constituição é concebida como direito vivo constitutiva da realidade social e não apenas como uma esfera autônoma que deve ser analisada nos seus próprios termos. Ela está, assim, associada a dinâmicas como as do momento constituinte, processos de revisão constitucional, influências do transconstitucionalismo, ou dinâmicas de mobilização e interpretação por movimentos, atores sociais e políticos, agentes econômicos, parceiros sociais, etc. (FERREIRA, 2016, p. 134).

Neste compasso, alguns dos objetivos do país, pautados na Constituição, passam a ser discutidos além das bases estatais, envolvendo dois ou até um conglomerado de países capazes de oferecer soluções a problemas transversais. Assim, a Constituição tende a não se limitar apenas em critérios puramente nacionais, passando também a abarcar metas transconstitucionais ${ }^{15}$ que envolvem diversos ordenamentos legais e sua gama de tribunais locais e internacionais. Neste sentido, as normativas internacionais, a exemplo das convenções da OIT, sobre direitos humanos do trabalhador (especificamente as que protegem 0 trabalhador infantojuvenil) recebem um peso maior na legislação pátria, bem como na proposição de políticas direcionais para o país.

Destaque-se também que um dos fenômenos ocasionados pelo neoconstitucionalismo é a constitucionalização do Direito. Este é termo bastante recente na terminologia jurídica, que comporta múltiplos sentidos. Barroso (2005) compreende a constitucionalização do Direito como um fenômeno jurídico que tem como característica primordial a expansão das normas constitucionais com irradiação por todo o sistema jurídico. Sarmento (2006) utiliza a terminologia ubiquidade constitucional para também definir esse fenômeno, assinalando a onipresença da Constituição em todo o ordenamento legal, inclusive afetando normas de proteção ao trabalho precoce.

Sarmento (2006) elenca duas características importantes da constitucionalização do Direito: a) a Constituição passa a tratar temas também da legislação infraconstitucional e b) os princípios constitucionais penetram no

15 Uma das principais características do transconstitucionalismo se mostra quando as normas internacionais e seus sistemas são utilizados de formas transversais para decidir casos com temáticas, na maioria das vezes, difusas e coletivas ao mesmo tempo. Para isso, o transconstitucionalismo opera através de um sistema de filtragem entre os ordenamentos jurídicos envolvidos, produzindo uma vinculação entre eles, sem a perda de autonomia estatal dos países entrelaçados (NEVES, 2009). Desse modo, esse entrelaçamento promove o aprendizado recíproco entre sistemas jurídicos diversos, sendo capaz de melhorar a eficácia e garantia dos direitos de crianças e adolescentes em questão. 
ordenamento legal, promovendo a filtragem constitucional. Neste sentido, essas duas grandes características apontadas por Sarmento impactam diretamente na melhoria do amparo à crianças e adolescentes contra a exploração de um trabalho precoce e irregular por trazer um status constitucional à proteção infantojuvenil.

\subsection{Impactos do Neoconstitucionalismo no combate ao trabalho infantojuvenil}

O neoconstitucionalismo brasileiro permitiu que o legislador tivesse como foco o cumprimento dos objetivos e princípios consagrados na Constituição Federal, dentre eles a proteção à infância e adolescência, com destaque para o princípio do melhor interesse da criança e do adolescente. Assim, políticas públicas de escolarização, distribuição de renda e também a destinação de verbas para a conscientização e combate ao trabalho infantojuvenil são frutos, também, dessa nova visão da Constituição como centro do ordenamento jurídico, num ideário neoconstitucionalista.

Nota-se o início de um período que marca a força normativa da Constituição, que passa a ter um papel de centralidade nos ordenamentos jurídicos, tornando-se fundamental na construção política e jurídica do Estado. Dentre os vários assuntos relevantes na Constituição Federal de 1988, destaca-se o capítulo VII: da Família, da Criança, do Adolescente, do Jovem e do Idoso. Este capítulo permitiu que o legislador infraconstitucional se norteasse na elaboração de novas leis voltadas à proteção da criança e do adolescente, a exemplo da proibição do trabalho precoce, e também para que o poder executivo instaurasse políticas públicas para concretização do disposto na Constituição Federal de 1988, a exemplo do Programa de Erradicação do Trabalho Infantil (PETI).

O neoconstitucionalismo permitiu a irradiação das normas constitucionais no Direito da Criança e do Adolescente, com foco na hermenêutica constitucional de prioridade de infantes e jovens, e na ponderação de princípios fundamentais, elevando a importância do tema infância e juventude. Ademais, instou a sociedade e um conjunto diversificado de atores sociais a se envolverem com a busca de soluções para este problema. Os atores jurídicos, por exemplo, participam ativamente (direta e indiretamente) do processo de enfrentamento ao trabalho infantojuvenil, seja na elaboração de leis, no controle de ato ilegais e violadores da Constituição Federal por entes públicos e privados (grande inovação do neoconstitucionalismo), ou na elaboração de políticas públicas com foco no cumprimento da Constituição Federal de 
1988. O neoconstitucionalismo também favoreceu o fortalecimento de instituições, com disposição expressa de competências na Constituição Federal, a exemplo do Ministério Público ${ }^{16}$,

Desta forma, o constitucionalizado Direito da criança e do adolescente no Brasil apresenta-se como um importante instrumento na elaboração de leis vinculadas a proteção do trabalho de crianças e adolescentes, além de forçar a criação de normas e programas sociais para combater as irregularidades no tocante à esfera trabalhista infantojuvenil.

Com o poder de impactar significativamente os direitos da criança e do adolescente, a constitucionalização do Direito gera efeitos na administração pública, a exemplo do fornecimento de fundamentos de validade para a prática direta e imediata de atos administrativos que favoreçam ações de proteção infantojuvenil. Também, seus efeitos são sentidos no poder judiciário sob influência nos parâmetros do controle de constitucionalidade adotados conforme a compreensão do sistema jurídico de proteção ao indivíduo menor de dezoito anos de idade. Ainda, no legislativo, a elaboração das leis passa a estar condicionada à Constituição e seus objetivos programáticos, inclusive os que ampliam o direito de crianças $e$ adolescentes.

Todas essas influências da constitucionalização do direito citadas no parágrafo anterior impactam diretamente na redução dos índices de trabalho infantojuvenil, haja vista que ao proteger e melhorar a condição de crianças e adolescentes com políticas públicas e elaboração de normas jurídicas, afasta-se esses indivíduos de atividades laborais impróprias.

Inobstante, tanto na esfera da aplicação das leis pelo judiciário, quanto na sua elaboração pelo poder legislativo, a Constitucionalização do Direito afeta consideravelmente o Direito da Criança e do Adolescente. O Artigo 227 da Constituição Federal tratou de elevar o seu grau de importância no ordenamento jurídico, estabelecendo absoluta prioridade na garantia de direitos como saúde,

\footnotetext{
${ }^{16}$ No combate ao trabalho infantojuvenil, o Ministério Público dispõe de instrumentos jurídicos como a ação civil pública, indispensável à garantia do direito de pessoas em situação de vulnerabilidade, contribuindo fortemente para a eficácia dos direitos fundamentais nas relações sociais e empresariais porque fornece ao Ministério Público um meio jurídico com rito próprio para a defesa de direitos coletivos e difusos. A ACP é fruto do processo de redemocratização brasileira e do Neoconstitucionalismo, que atribuiu ainda ao Ministério Público outras ferramentas importantes na defesa e na ampliação do acesso à justiça, a exemplo do inquérito civil e o termo de ajustamento de conduta. Assim, o parquet aumentou a sua independência em relação aos poderes (executivo, legislativo e judiciário), passando a gozar de autonomia funcional e administrativa (RIBEIRO, 2017).
} 
liberdade, convivência familiar, educação, dentre outros. Ainda, estabelece um tripé de responsabilidades ao imputar à família, à sociedade e ao Estado o dever de assegurar esses direitos à criança e ao adolescente, inclusive a proteção contra o trabalho indecente e precoce.

Se antes da constitucionalização a criança era vista como ser produtivo (mãode-obra barata para o sistema econômico), hoje tem suas atividades laborais limitadas conforme sua condição peculiar de desenvolvimento e amplamente garantidas pela Constituição e legislação infraconstitucional, haja vista que o direito desses indivíduos se insere também no rol de cláusulas pétreas, não podendo ser alterados, mas apenas ampliados.

Por ora, cabe indicar que o enfretamento ao trabalho infantojuvenil encontra um grande aliado na constitucionalização do Direito, seja pela elaboração de normas infraconstitucionais que criem mecanismos de combate, ou de criminalização, seja também pela influência na elaboração de políticas públicas.

\section{CONSIDERAÇÕES FINAIS}

O presente trabalho colocou em discussão o neoconstitucionalismo frente ao combate do trabalho infantojuvenil no Brasil. Neste percurso, foi possível perceber as contribuições e perspectivas que a constitucionalização oferece para as soluções de erradicação do trabalho precoce.

A Constituição brasileira proíbe o trabalho de pessoas menores de dezesseis anos, salvo, a partir dos quatorze anos, na condição de aprendiz. Também, é proibido o trabalho perigoso e insalubre aos menores de dezoito anos de idade. Logo, o Direito Constitucional brasileiro compreende a proteção ao trabalho como um direito fundamental social com a finalidade de promover a dignidade humana e o desenvolvimento de toda a sociedade.

As transformações no Estado de Direito, tendo como centro do ordenamento jurídico a Constituição, dotada de força normativa vinculante, exige que as regras infraconstitucionais protetivas sejam cada vez mais valoradas conforme a Carta Magna, que dispõe de diversos dispositivos voltados à proteção da criança e do adolescente

Um dos principais desafios no enfretamento ao trabalho infantojuvenil está justamente na elaboração e efetivação de políticas públicas que promovam o 
rompimento do ciclo de pobreza. Através de programas de distribuição de renda, políticas de emprego, ações afirmativas e inclusivas, famílias, adolescentes e crianças poderão enxergar um horizonte além da exploração precoce de seu trabalho. Romper o ciclo de exclusão exige um conjunto articulado de ações, que inclui conscientizar as classes economicamente mais favorecidas do prejuízo causado pelo trabalho irregular de crianças e adolescentes.

Por tudo o que foi apresentado, o neoconstitucionalismo contribuiu com a adoção de ferramentas para combater o desemprego, a pobreza e a falta de educação, aspectos que devem ser vistos como a pauta prioritária em decorrência de fazer valer o Estado Constitucional e a própria Constituição como um guia, características fundamentais do fenômeno do neoconstitucionalismo.

As experiências dos programas já realizados, Programa de Erradicação do Trabalho Infantil (PETI) e o programa Jovem Aprendiz, ambos no âmbito do Poder Executivo Federal, são ilustrativas neoconstitucionais de como princípios constitucionais e normas se irradiaram para todo o sistema.

A interpretação sistemática de direitos fundamentais e, também, a irradiação das normas constitucionais na administração pública possibilitam realizar políticas de transferência de renda para as famílias, e de experiências de profissionalização e primeiro emprego para adolescentes em idade adequada ao exercício de atividades laborais.

Outrossim, o impulsionamento do neoconstitucionalismo alcança uma melhor definição dos papéis institucionais, de modo que esforços e investimentos sejam envidados para a conscientização da população brasileira e com foco na escolarização e na inserção no mercado de trabalho de forma decente, o que significa respeito e à idade e a condição de desenvolvimento.

Portanto, confirmando a hipótese do presente artigo, restou demonstrado que o trabalho infantojuvenil, que se arrasta por toda a história da humanidade, encontrou uma barreira para a sua progressão e perpetuação no neoconstitucionalismo, que se apresenta como um aliado na erradicação do trabalho precoce, irregular e violador de direitos fundamentais.

\section{REFERÊNCIAS}

ARIĖS, Philippe. História Social da Criança e da Família. Rio de Janeiro: LTC, 2017. 
BARROS, Alice Monteiro de. Curso de Direito do Trabalho. 10 ed. São Paulo: LTr, 2016.

BARROSO, Luís Roberto. Neoconstitucionalismo e constitucionalização do direito: o triunfo tardio do direito constitucional no brasil. Revista de Direito Administrativo, v. 240, p. 1-42, 2005.

LEITE, Carlos Henrique Bezerra. Curso de direito do trabalho. São Paulo: Saraiva, 2017.

BRASIL. III Plano Nacional de Prevenção e Erradicação do Trabalho Infantil e Proteção ao Trabalhador Adolescente. Disponível em: < http://www.fnpeti.org.br/arquivos//biblioteca/6fad0abfbf9ae814ea68ab00476ba502.pd f >. Acesso em: 21 maio 2019.

Constituição da República Federativa do Brasil de 1988. Disponível em: < http://www.planalto.gov.br/ccivil_03/constituicao/constitui\%C3\%A7ao.htm > Acesso em: 18 maio 2019.

. Consolidação das Leis Trabalhistas de 1943. Disponível em < http://www.planalto.gov.br/ccivil_03/decreto-lei/Del5452.htm > Acesso em: 17 maio 2019.

Decreto 5.598 , de $1^{\circ}$ de dezembro de 2005. Regulamenta a contratação de aprendizes e dá outras providências. Disponível em < http://www.planalto.gov.br/ccivil_03/_ato2004-2006/2005/decreto/d5598.htm > Acesso em: 18 maio 2019.

Decreto 99.710, de 21 de novembro de 1990. Promulga a convenção

sobre Direitos da Criança. Disponível em <
http://www.planalto.gov.br/ccivil_03/decreto/1990-1994/d99710.htm> Acesso em: 19 maio 2019.

Estatuto da Criança e do Adolescente de 1990. Disponível em < http://www.planalto.gov.br/ccivil_03/leis/L8069Compilado.htm > Acesso em: 18 maio 2019.

. Lei n 13.257, de 08 de março de 2016. Dispõe sobre as políticas públicas para a primeira infância. Disponível em: http://www.planalto.gov.br/ccivil_03/_ato2015-2018/2016/lei/l13257.htm>. Acesso em: 16 maio 2019.

Lei $\mathrm{n}^{0}$ 12.852, de 05 de agosto de 2013. Institui o Estatuto da Juventude e dispõe sobre os direitos dos jovens, os princípios e diretrizes das políticas públicas de juventude e o Sistema Nacional de Juventude - SINAJUVE. Disponível em: <http://www.planalto.gov.br/ccivil_03/_ato20112014/2013/lei/l12852.htm>. Acesso em: 17 maio 2019.

CASSAR, Vólia Bomfim. Direito do Trabalho. São Paulo: Método, 2017. 
CAVALCANTE, Sandra Regina. Trabalho infantil artístico: conveniência, legalidade, e limites. Revista do Tribunal Superior do Trabalho, São Paulo, v. 79, n. 1, p. 139-158, jan./mar. 2013.

DELGADO, Maurício Godinho. Curso de direito do trabalho. São Paulo: LTr, 2017.

DIAS, Fábio Muller Dutra; LIBERATI Wilson Donizeti. Trabalho infantil. São Paulo: Método, 2006.

DUPRET, Cristiane. Curso de Direito da Criança e do Adolescente. $3^{a}$ ed. Belo Horizonte: Letramento, 2015.

FERREIRA, Antonio Casimiro. A constituição ainda é uma escolha política. In: Aprova do tempo: quarenta anos de constituição portuguesa. Lisboa: Assembleia da República, 2016.

GONTIJO, Manfredo Schwaner. Constitucionalismo: evolução características, tendências. Belo Horizonte: Do Autor, 2015.

MOREIRA, Eduardo Ribeiro. Neoconstitucionalismo: a invasão da constituição. São Paulo: Método, 2008.

MOREIRA, Rafael Bueno da Rosa; CUSTÓDIO, André Viana. A influência do Direito Internacional no processo de erradicação do trabalho infantil no Brasil. Revista Direitos Fundamentais e Democracia, v. 23, n. 2, p. 178-197, mai./ago. 2018.

NEVES, Marcelo. Transconstitucionalismo. São Paulo: WMF Martins Fontes, 2009.

OZELLA, Sérgio. Adolescências construídas: a visão da Psicologia sóciohistórica. São Paulo: Cortez, 2003.

PIAGET, Jean. Seis estudos sobre Psicologia. Rio de Janeiro: Forense Universitária, 1999.

PIOVESAN, Flavia. Direitos Humanos e o Direito Constitucional Internacional. São Paulo: Saraiva, 2013.

REIS, Jair Teixeira dos. Direito da criança e do adolescente: questões trabalhistas infantojuvenis. Campinas: Lacier, 2011.

RIBEIRO. Ludmila Mendonça Lopes Ribeiro. Ministério Público: Velha instituição com novas funções? Revista Crítica de Ciências Sociais v. 113, p. 51-82, 2017.

ROCHA, Rita de Cássia Luiz da. História da infância: reflexões acerca de algumas concepções correntes. Revista Analecta, v. nº 02, p. 51-63, 2002.

SARAIVA, João Batista Costa. Compêndio de direito penal juvenil: adolescente e ato infracional. Porto Alegre: Livraria do advogado, 2010. 
SARLET, Ingo Wolfgang. Dignidade da pessoa humana e direitos fundamentais na constituição federal de 1998. Porto Alegre: Livraria do Advogado, 2011.

SARMENTO, Daniel. Livres e Iguais: estudos de Direito Constitucional. Rio de Janeiro: Lumen Juris, 2006.

SHAFFER, David. Psicologia do desenvolvimento: infância e adolescência. São Paulo: Pioneira, 2005.

SILVA NETO, Manoel Jorge e. O constitucionalismo brasileiro. Brasília: ESMPU, 2016.

SILVA, Virgílio Afonso da. A constitucionalização do Direito: os direitos fundamentais nas relações entre particulares. São Paulo: Malheiros, 2014.

SOUSA, Otávio Reis de; PESSOA, Flávia Moreira Guimarães. Iniciação ao Direito do Trabalho: um estudo a partir dos direitos fundamentais. Aracaju: Evocati, 2016.

SPOSATO, Karyna Batista. Criança, democracia e neoconstitucionalismo no Brasil. Revista Diké - Mestrado em Direito, v. 4, p. 157, 2015.

TOURAINE, Alain. Crítica da modernidade. Petrópolis: Rio de Janeiro, 1994.

TREVISAM, Elisaide. Trabalho escravo no Brasil contemporâneo: entre as presas da clandestinidade e as garras da exclusão. Curitiba: Juruá, 2015.

VAINER, Bruno Zilberman. A força normativa da constituição como garantidora da segurança jurídica: uma análise das obras de Konrad Hesse e de Ferdinand Lassalle. Revista Brasileira de Direito Constitucional, n 10, p. 91-100, 2007.

Recebido em 31/01/2019

Aprovado em 22/11/2019

Received in 31/01/2019

Approved in 22/11/2019 